\title{
Genetic Diversity of Plant Species IN GLACIER NATIONAL PARK: IMPLICATIONS FOR MANAGEMENT
}

\author{
ThOMAS MITCHELL-OLDS $\downarrow$ DIVISION OF BIOLOGICAL SCIENCES \\ UNIVERSITY OF MONTANA $\bullet$ MISSOULA
}

\section{EXECUTIVE SUMMARY}

Genetic diversity, as the fundamental resource of Glacier National Park (GNP), is central to the characterization of biodiversity present in GNP. Preserving the genetic variation in species maintains their intrinsic flexibility to deal with variable abiotic and biotic environments. Although often not readily apparent as visible morphologic (phenotypic) differences, genetic variation may occur 1) between individuals within a population and 2) between populations of a species. Managers need to consider these two components of genetic variation when mediating the effects of human disturbance in GNP. However, very little is currently known about these levels of genetic organization in GNP species.

Our three year project examines the presence and patterns of genetic variation in two GNP species: strawberry (Fragaria virginiana Duchesne) and mountain brome (Bromus carinatus Hook. and Arn.). We are quantifying the amount and distribution of genetic and phenotypic variation using quantitative genetic and electrophoretic methods and are identifying phenotypic characters subject to natural selection, i.e., those characters important for survival and reproduction differences in populations.

\section{QUANTITATIVE GENETICS}

Individual plants may differ genetically by variation among many genes that have small effects, forming a continuum of phenotypes. Quantitative genetic methods assess genetic variation by measuring the phenotypic traits of related individuals (e.g., one genotype and its clones). Transplants from six GNP strawberry populations (360 individual plants) have been propagated since June 1990 in Diettert Experimental Gardens, University of Montana. Strawberries reproduce asexually by developing small plantlets on a runner (=clones). These clones are genetically identical to the original (or maternal) strawberry plant. During the 1991 growing season, maternal strawberries produced 1018 clones. Clones, placed in pots, are in a randomized complete block design in the garden. Since the original experimental design called for 3600 clones, the strawberry clones are overwintering at UM. Hopefully, more plantlets will be produced from these clones and the maternal strawberries in 1992.

\section{ELECTROPHORESIS}

Electrophoresis can reveal genetic polymorphisms of isozymes and give estimates of the amount of genetic variation present within a population. During our first field season, dormant strawberry leaves were harvested during Oct./Nov. 1990 for electrophoresis. Subsequent analysis revealed that proteins (enzymes) from dormant leaves are broken down; therefore, electrophoretic trials were unsuccessful. Young leaves from the 360 plants were harvested again during June 1991. Leaves were ground in two buffers, phosphate-PVP and 
tris-maleate-PVP and stored at -80C. Electrophoretic screening to resolve enzyme systems continues during fall 1991.

Mountain brome seeds have been germinated for six GNP populations and Bridger Plant Materials Center accessions. Seedlings were ground in the two buffers mentioned above and stored at $-80 \mathrm{C}$. Electrophoretic screening for resolution of enzymes and polymorphic loci continues during fall 1991 and winter 1992.

\section{NATURAL SELECTION}

Measurements of varying phenotypic traits in strawberries can indicate differences in fitness (i.e., survival and reproduction). At the beginning and end of the 1991 growing season, 200 labeled strawberry plants in each of six GNP populations were relocated and characters measured. For plants in lower elevation populations (Belton Hills, Big Prairie, Wilbur Creek, and Lower Two-Medicine), measurement times were two and five months after the snow receded (June and September). At Logan Pass and Siyeh Creek populations, the same proportion of time after snow melt and before snow fall was used; plants were measured at three weeks and again at two months (August and September). These data will be compared with 1990 data to estimate temporal/spatial differences in natural selection.

Plant tags on the study population at Belton Hills were vandalized between fall 1990 and spring 1991, with 74 tags removed or destroyed out of the 200 experimental strawberry plants. New plants were chosen randomly and tagged in August to replace those vandalized.

\section{- PROPOSED WORK}

\section{November 1991 to 31 May 1992}

During the remainder of this second year of a three year study, experiments to characterize genetic variation in natural populations in GNP will continue: 1) quantitative genetics, 2) electrophoresis, and 3 ) natural selection. The first part of this year has been spent collecting data and potting strawberry clones. Two main tasks to be completed this year are electrophoresis on both species and data analysis for all experiments.

\section{QUANTITATIVE GENETICS}

This experiment provides information on the genetic differentiation and local adaptation of strawberry populations. Maternal strawberries and their 1991 clones will be monitored for production of plantlets. Experimental planting designs will be modified to accommodate the number of clones produced by early June 1992. Final clone numbers for transplant depend upon winter mortality and spring asexual reproduction rates. Clones will be transplanted into three common environments: 1) low elevation west side (Headquarters, West Glacier, 975 $\mathrm{m})$, low elevation east side (400 $\mathrm{m}$ up the Red Eagle Trail, $1372 \mathrm{~m}$ ), and high elevation (Werner Mt, Whitefish Range, Flathead NF, $2070 \mathrm{~m})$. Quantitative characters will be measured in June when clones are initially transplanted and again in August at the end of the growing season.

\section{ELECTROPHORESIS}

Electrophoretic screening and analyses for polymorphic loci will continue for both strawberry and mountain brome. Analysis of all electrophoretic data will use measures of genetic distance and $F$ statistics (Nei 1987). Tests of statistical significance will use parametric (Sokal and Rohlf 1981) and nonparametric techniques (Mitchell-Olds 1986).

\section{NATURAL SELECTION}

These analyses will help to identify the factors that determine variation in strawberry survival and reproduction (i.e., fitness) and, therefore, on revegetation success. Second year data from the six populations will be compared with first year data. Regression significance tests will be used to estimate the effects of various characters on fitness components (Mitchell-Olds 1986, Mitchell-Olds and Bergelson 1990).

\section{$\checkmark \quad$ CONCLUSIONS}

The results of our three year study will reveal whether genetic divergence has occurred along environmental and geographic gradients in GNP. To preserve ecologically and evolutionarily important genetic variation, we must identify genetic differentiation and local adaptation among populations, quantify the distribution of isozyme 
genetic variation between populations and between geographic areas, and discover which characters are subject to natural selection in the wild. This information will indicate necessary steps for managers to effectively maintain genetic diversity currently present in the park. Our research will identify potential impacts to genetic diversity in GNP resulting from revegetation activities.

\section{LITERATURE CITED}

Mitchell-Olds, T. 1986. Discussion of C. F. J. Wu's "Jackknife, bootstrap, and other resampling methods in regression analysis". Ann. Statis. 14:1316-1318.
Mitchell-Olds, T. and J. Bergelson. 1990. Statistical genetics of an annual plant, Impatiens capensis. II. Natural selection. Genetics 124:417-421.

Nei, M. 1987. Molecular Evolutionary Genetics. NY:Columbia University Press.

Sokal, R. and J. Rohlf. 1981. Biometrics. NY:Freeman. 